\title{
IMPORTÂNCIA DA EDUCAÇÃ்O EM SERVIÇO NA DIMINUIÇÃO DA CONTAMINAÇÃO DAS AMOSTRAS PARA UROCULTURA*
}

\author{
Thais Valença Ribeiro Ricardi** \\ Elisa Halker*** \\ Maria Teresa G.F. Sato**** \\ Fernanda P. Carratu*****
}

\begin{abstract}
RESUMO - O Laboratório de Microbiologia do Hospital São Paulo detectou um aumento no número de amostras de urina contaminada, no perlodo de janeiro a agosto, em 1988. Observou-se que o problema foi a utilização incorreta da técnica de coleta daquelas amostras. Então, com a finalidade de treinar a equipe de enfermagem, foi elaborado um programa de estudo pelas enfermeiras do Centro de Estudos de Enfermagem, Comitê de Controle de Infecção e Laboratório. Depois desse programa o número de amostras contaminadas teve uma significativa redução, principalmente no setor de pediatria. Os autores concluiram que a educação continuada aperfeiçoa a prática de enfermagem no hospital e dá uma motivação profissional à categoria.
\end{abstract}

ABSTRACT - The Microbiology Laboratory of São Paulo Hospital detected a
increased number of contaminated urine samples, in the period from January to
August, in 1988. It was observed that the problem was an incorrect technic in
collecting those samples. So, in order to train the nursing staff, it was elaborated
a study program by the nurses of Nursing Study Center, Infection Control
Committee, and Laboratory. After this program the rate of contaminated samples
had an important reduction, meanly in pediatrics wards. The authors concluded
that the continuing education improves nursing practives in hospital and gives
professional motivation to the staff.

\section{INTRODUÇÃO}

Segundo ANDRIOLE ${ }^{1}$, as infecções do trato urinário (ITU) representam uma das doenças infecciosas mais encontradas na prática médica. Por esta razão, tem sido realizada uma intensa investigação de sua epidemiologia, durante as três últimas décadas.

EDEN \& De $\mathrm{MAN}^{2}$ ressaltam que as infecções do trato urinário podem ser causadas por uma ampla variedade de bactérias Gram negativas e Gram positivas, as quais também são constituintes da flora normal. A maioria dos patógenos do trato urinário originam-se do trato intestinal.

As ITUS provocam intenso desconforto a seus portadores e, embora facilmente erradicadas na maioria dos pacientes são, às vezes, responsáveis por sintomas crônicos ou manifestações mais graves, como septicemia por Gram negativos e morte ${ }^{2}$. Além disso, requerem elevados recursos financeiros ao tratamento da infecção.

A confirmação da ITU requer a identificação da bactéria na urina, a qual é normalmente estéril. Devido à dificuldade em se obter urina diretamente da bexiga, a cultura é geralmente realizada na urina eliminada por micção. A este exame denomina-se urocultura.

JOHNSON, STAMM ${ }^{3}$, descrevem que, como a urina é facilmente contaminada por bactérias peri- neais, utiliza-se a cultura quantitativa e a identificação específica do patógeno para se distinguir os contaminantes (contagem reduzida) dos reais patógenos (contagem elevada).

O resultado de uma contagem de colônias é significativo se existirem números maiores que 100.000 colônias por mil, desde que o material tenha sido colhido nas seguintes condições: a área periuretral cuidadosamente lavada com água e sabão, com posterior aplicação de antisséptico específico; a amostra colhida de jato médio, enviada ao laboratório num recipiente esterelizado e mantida sob refrigeração até a semeadura para a contagem de colônias.

Segundo WALLACH ${ }^{4}$, um resultado positivo numa amostra única contendo bacilos Gram negativos, tem uma probabilidade de $85 \%$ de ser igual à amostra seguinte (i.e., um erro de $15 \%$ na determinação em amostra única). Valores maiores que 10.000 colônias por $\mathrm{ml}$, na ausência de terapêutica antimicrobiana, não excluem o diagnóstico de ITU. Pode-se encontrar resultados falsos negativos quando há um elevado débito urinário, baixa densidade da urina, $\mathrm{pH}$ urinário baixo, medicamentos antibacterianos na urina ou quando as culturas não forem feitas com técnica apropriada.

Sabe-se que as implicações decorrentes da coleta

\footnotetext{
* Prêmio Noraci Pedrosa - 3 Lugar - 41 Congresso Brasileiro de Enfermagem - Florianópolis-SC

** Enfermeira do Centro de Estudos do Hospital São Paulo

*** Enfermeira da CCIH do Hospital São Paulo

**** Enfermeira do Centro de Estudos do Hospital São Paulo

***** Enfermeira da CCIH do Hospital São Paulo
} 
inco reta são de extrema gravidade, pois isso pode significar um maior período de internação do paciente no aguardo de conduta médica, gasto desnecessário de material, gasto de tempo do funcionário de enfermagem e do laboratório além de terapêutica inadequada.

No Hospital São Paulo, no período de janeiro a agosto de 1988 , foi detectado pelo laboratório de microbiologia um número elevado de uroculturas contaminadas, impossibilitando desta maneira o diagnóstico das ITUs.

Frente ao problema exposto, foi solicitado ao Setor de Educação em Serviço do Centro de Estudos da Divisão de Enfermagem e à Comissão de Controle de Infecção Hospitalar, uma reciclagem para funcionários da enfermagem, que abordasse técnica correta para coleta de tal exame.

O objetivo deste trabalho é o de avaliar a efetividade da reciclagem desenvolvida pelas enfermeiras da CCIH, Centro de Estudos da Divisão de Enfermagem e Laboratório de Microbiologia, para coleta correta de urocultura, aplicada aos funcionários de enfermagem do Hospital São Paulo.

\section{MATERIAL E MÉTODOS}

HOSPITAL SÃO PAULO - O Hospital São Paulo é uma instituição de ensino da Escola Paulista de Medicina, localizado na capital.

É um hospital geral, com 600 leitos, divididos em 29 unidades de internação, de acordo com as especialidades médicas existentes.

A média de permanéncia no ano de 1988 foi de 9,48 dias e o coeficiente de ocupação, de 85,28\%.

CENTRO DE ESTUDOS DA DIVISÃO DE ENFERMAGEM - Criado em 1983, pela Diretoria da Divisão de Enfermagem, para a sistematização de 'ações visando o desenvolvimento de recursos humanos dentro de um planejamento integrado, obtendo-se dessa maneira a melhoria do nível de conhecimento e desempenho do pessoal de enfermagem.

O Centro de Estudos é composto por três enfermeiros com dedicação em tempo integral. Cabe ao mesmo desenvolver atividades ligadas aos seus setores:

- Educação em Serviço;

- Científico;

- Social.

O Setor de Educação em Serviço, responsabiliza-se pelo dimensionamento do pessoal de enfermagem, por sua admissão, e treinamento, atế seu desligamento da Ins tituição.

COMISSÃO DE CONTROLE DE INFECÇÃO HOSPITALAR (CCIH) - NÚCLEO EXECUTIVO - Em março de 1985, por iniciativa da direção clínica do Hospital São Paulo, foi constituída a Comissão de Controle de Infecção Hospitalar (CCIH), formada por representantes médicos dos quatro departamentos (Cirurgia, Clínica Médica, Tocoginecologia e Pediatria) e do Laboratório de Microbiologia, representantes da Divisão de Enfermagem, da Farmácia, da Diretoria e de outros setores envolvidos com infecção hospitalar.

Esta Comissão dispõe do Núcleo Executivo, que conta com dois médicos especialistas em Doenças Infecciosas e Parasitárias e três enfermeiros, com dedicação em tempo integral.

Entre outras funções, cabe ao enfermeiro da
CCIH, a orientação aos programas de treinamento em serviço relacionados ao controle de infecções.

LABORATÓRIO - O laboratório de microbiologia do Hospital São Paulo está funcionando atualmente em prédio anexo ao Hospital. Conta com uma equipe profissional formada por: três médicos, um enfermeiro, um bioquímico, cinco biomédicos, um técnico de laboratorio.

Em sua rotina diária, são analisados 70 a 100 exames de urina para cultura por dia, abrangendo além dos pacientes internados, pacientes do pronto socorro, ambulatoriais e conveniados.

A rotina usada para cultura de urina realizada pelo laboratório de microbiologia segue em anexo 1.

PERÍODO DE ESTUDO - A partir da solicitação feita pelo Laboratório de microbiologia, foi plane jado um programa de reciclagem aos funcionários de enfermagem em novembro de 1988 e sua aplicação deu-se a partir do final do dito mês até janeiro de 1989.

PROGRAMA DE RECICLAGEM - A montagem do procedimento deu-se da seguinte forma: seleção de antissépticos e de material necessário para o procedimento, adequação da técnica e tipo de funcionário a ser treinado.

Foi, então, elaborada uma apostila contendo conceitos, tipos de procedimentos, ligados ao sexo, idade e condições em que o paciente se encontrava (acamado, deamdulante e cateterizado - anexo 2). O período de treinamento foi estipulado em dois meses, com aulas nos três períodos (manhã, tarde e noite).

A divulgação foi feita através de cartazes anexados em todos os andares do Hospital e circulares distribuídas para os enfermeiros das diferentes unidades de internação e setores diversos.

A reciclagem foi direcionada apenas aos enfermeiros e auxiliares de enfermagem. A convocação se deu através de escalas, elaboradas pelos supervisores de enfermagem.

As aulas foram ministradas pelas enfermeiras do Centro de Estudos, CCIH e laboratório de microbiologia.

A didática usada foi:

- aula expositiva, com retroprojeção de figuras ilustrativas (anexo 3), demonstrando em classe a técnica correta e material necessário;

- discussão de virtuais situações encontradas pelos funcionários;

- propostas de soluções encontradas em conjunto pelas enfermeiras e funcionários.

ESTATÍSTICA - Foram aplicados aos dados obtidos pré e pós programa de reciclagern, os testes exato de Fisher e Qui Quadrado, para avaliar significância.

\section{RESULTADOS}

Foi feito um levantamento retrospectivo pré programa de reciclagem para comparação posterior aos dados obtidos pós programa. Os resultados obtidos foram:

Período anterior à reciclagem:

- amostras colhidas: 940

- amostras contaminadas: 77

Estas amostras foram enviadas de diversas unidades de internação do Hospital (adulto e infantil).

Período posterior à reciclagem: 
- amostras colhidas: 892

- amostras contaminadas: 63

Para o estudo, foram usadas amostras das mesmas unidades de internação do período acima.

As amostras obtidas podem ser observadas abaixo:

TABELA 1 - Porcentagem de uroculturas contaminadas, antes e após o programa de reciclagem aplicado aos funcionários de enfermagem sobre técnica de coleta de urina para cultura. São Paulo 1988/1989.

\begin{tabular}{|c|c|c|c|c|c|c|}
\hline \multirow{3}{*}{ Unidades } & \multicolumn{3}{|c|}{ Antes } & \multicolumn{3}{|c|}{ Depois } \\
\hline & \multirow{2}{*}{ Colhida } & \multicolumn{2}{|c|}{ Contaminada } & \multirow{2}{*}{ Colhida } & \multicolumn{2}{|c|}{ Contaminada } \\
\hline & & f & $\%$ & & $\mathbf{f}$ & $\%$ \\
\hline P.S. GERAL & 212 & 22 & 10.4 & 239 & 25 & 10.4 \\
\hline P.S. PEDIAT* & 119 & 19 & 16.0 & 123 & 12 & 9.7 \\
\hline LEITOS ADULT & 554 & 32 & 6.0 & 488 & 23 & 4.7 \\
\hline LEITOS PEDIA & 55 & 4 & 7.3 & 42 & 3 & 7.1 \\
\hline Total & 940 & 77 & 8.1 & 892 & 63 & 7.0 \\
\hline
\end{tabular}

Fonte: Laboratório de microbiologia - Hospital São Paulo.

*Aplicado Qui Quadrado obtendo-se signficância de p(0.0005.

Obteve-se na reciclagem aplicada aproximadamente $85 \%$ de presença dos funcionários da enfermagem, além de voluntários do laboratório de microbiologia.

\section{DISCUSSÃO}

Segundo a tabela 1 , observa-se a diminuição, na maioria das unidades, entre as taxas comparadas de dados antes e apos o programa de reciclagem, o que nos permite acreditar no resultado positivo da aplicação de tal programa.

A redução mais importante deu-se no Pronto Socorro de pediatria, talvez pela mudança de conduta no uso do coletor estéril, descartável e aderente. Anteriormente à reciclagem, o mesmo era trocado com uma frequência de 15 em 15 minutos e sem antissepsia entre as trocas. Segundo a orientação dada, passou-se a trocá-lo com maior intervalo de tempo e com antissepsia prévia. Outro fator importante notado foi de que a urina era transferida do coletor aderido à região perineal da criança, para o tubo estéril, podendo nessa transferência haver contaminação. Foi proposto, então, o encaminhamento do próprio coletor, com a urina, ao laboratório de microbiologia.

Em relação aos funcionários, notou-se grande interesse e participação por parte dos mesmos, levando-nos a crer ainda mais na necessidade de desenvolver técnicas de ensino que estimulem o funcionário a melhorar a assitência de enfermagem prestada aos pacientes.

\section{CONCLUSÃo}

Para obter-se a identificação das ITUs é imprescindível que a técnica correta seja aplicada no ato da coleta, com o intuito de isenta-la de possíveis contaminação. Com isso, proporciona-se ao paciente menor tempo de internação e, ao Hospital, menor custo.

Podemos observar nesse trabalho que a educação continuada teve um papel importante na diminuição do número de amostras de uroculturas contaminadas, levando dessa maneira à melhoria da assistência de enfermagem e motivação profissional dos funcionários. Portanto investir nesse setor dentro do hospital proporciona sempre resultados positivos, tanto para os pacientes como para a instituição.

\section{ANEXO 1}

\section{LABORATÓRIO CENTRAL - SETOR DE MICROBIOLOGIA - EXAMES DE CULTURA}

AMOSTRA COLHIDA - Receber a amostra de urina colhida em condições adequadas de antissepsia, em tubo estéril, fornecido pelo laboratório.

MATERIAL NECESSÁRIO - a. Alça calibrada com diametro $0.001 \mathrm{~mm}$ (diluição de 1:1000).

b. Alça de Drigalski.

c. Placa de Petri.

MEIOS UTILIZADOS - a. Placas de Agar Sangue.

b. Placas de Agar - Teague.

c. Placas de Mueller - Hilton (Teste de susceptibilidade).

PROCEDIMENTO - ISOLAMENTO

URINA JATO MÉDIO - a. Homogeinizar o tubo com a urina colhida.

b. Utilizar a alça calibrada, flambar e imergir na amostra de urina colhida.

c. Transferir a urina contida na alça fazendo uma estria central em:

- 1 Placa de Agar - Sangue

- 1 Placa de Agar - Teague

d. Utilizar a alça de Drigalski, flambar levemente, resfriar na tampa da placa e semear a urina sobre toda a superfície do meio, na placa.

e. Incubar as placas a $37^{\circ} \mathrm{C}$. por $18-24$ horas.

URINA SUPRA PÚBICA - a. A urina colhida por punção supra púbica é semeada em:

- 1 Placa de Ágar - Sangue

Semear esta placa com a urina sem diluição.

- 1 placa de Agar - Sangue

- 1 Placa de Agar - Teague

Semear estas placas com a urina diluída $1 / 1000$, seguindo o mesmo procedimento descrito para a urina de jato médio.

LEITURA DAS PLACAS - a. Contar o número de colônias da placa.

b. Multiplicar o número de colônias x 1000 quan- 
Jo a urina for diluída $1 / 1000$. O número de colônias da urina sem diluição corresponde aquele contado diretamente da placa.

PROCEDIMENTO - IDENTIFICAÇÃO - Escolher as colônias e seguir a identificação adotada pelo laboratório para microorganismos Gram-positivos e Gram-negativos.

TESTE DE SUSCEPTIBILIDADE - Seguir a tếcnica de Kirby e Bauer.

LIBERAÇĀO DO LAUDO - a. Anotar o nome $\mathrm{da}(\mathrm{s})$ bactéria(s) isolada(s) e o(s) teste(s) de susceptibilidade.

b. Assinar, datar e enviar para a secretaria.

\section{ANEXO 2}

\section{COLETA DE URINA PARA UROCULTURA}

Conceito: Consiste na coleta de uma amostra de urina de jato médio para análise microbiológica. mado

$$
1 \text { - Paciente adulto sem sonda vesical - aca- }
$$
Material Necessário:
a) - bande ja
b) - jarro com água morna;
c) - sabão líquido;
d) - PVPI aquoso;
e) - gazes;
f) - luva cirúrgica estéril;
g) - comadre;
h) - biombo;
i) - impermeável;
j) - lençol;
k) cúpula limpa;
l) - tubo estéril p/urocultura;
m) - papel higiênico;
n) - saco plástico p/lixo;

\section{Procedimento na Mulher}

a) - lavar as mãos;

b) - reunir todo o material na bandeja e levá-lo junto à paciente;

c) - explicar à paciente o procedimento;

d) - cercar a cama com biombo, fechar portas e janelas;

e) - forrar a cama com o impermeável e sobre este, o lençol, na altura dos quadrís da paciente;

f) - expor a região genital;

g) - colocar a paciente em posição ginecológica e, em seguida colocar a comadre sob o quadrís;

h) - calçar as luvas;

i) - jogar água morna no perímetro;

j) - ensaboar com auxílio de gazes a região pubiana, em seguida os grandes lábios, pequenos lábios e vagina, sempre num sentido único de cima para baixo, utilizando tantas gazes quantas forem necessárias;

k) - desprezar as gazes utilizadas, no saco de lixo;

l) - enxaguar o períneo, jogando água e retirar o excesso de sabão com o auxílio de gazes, deixando o mais seco possível;

m) - colocar algumas gazes na cúpula e embebêlas com PVPI aquoso;

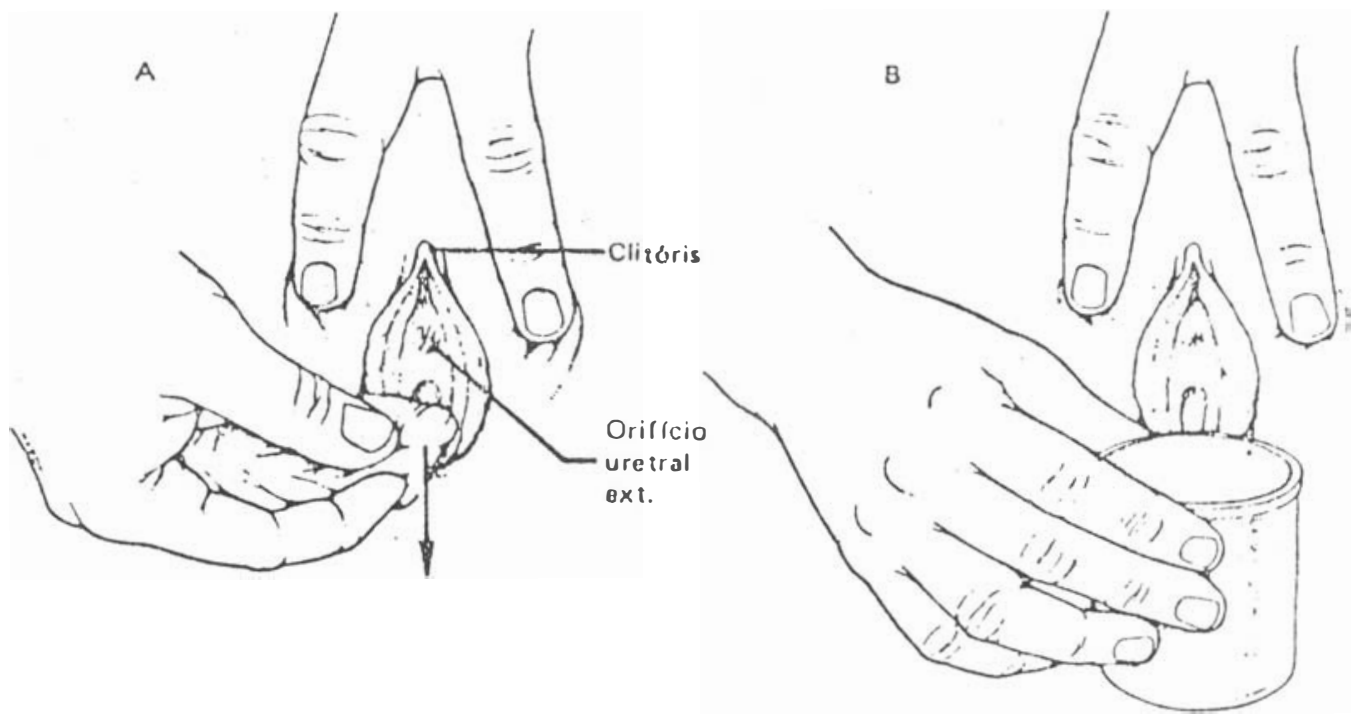

n) - afastar os pequenos lábios com a mão esquerda, para expor o orifício uretral;

o) - aplicar com a outra mão, gaze embebida em PVPI aquoso nos pequenos lábios e uretra e em seguida na vagina, sempre num sentido único de cima para baixo, sem retomar a face já usada da gaze, repetindo três vezes o procedimento; p) - secar com gaze, para retirar o excesso de PVPI;

q) - desprezar as gazes utilizadas, no saco de lixo;

r) - retirar o algodão do tubo estéril, com cuidado para não contaminar a parte interna deste e a borda do tubo, segurando-os na mesma mão;

s) - abrir os pequenos lábios com a mão esquerda e pedir à paciente para que urine com força; 
t) - colher o jato médio da micção diretamente no tubo estéril, não ultrapassando a metade deste;

u) - fechar o tubo com cuidado, para que a face contaminada do algodão fique para fora;

v) - apoiar o tubo em local seguro, para não cair;

x) - secar o períneo da paciente, com papel higiênico;

y) - recolher todo o material utilizado, deixando o ambiente em ordem e a paciente confortável;

w) - identificar o tubo com: nome completo da paciente, RG e no do leito, encaminhando-a em seguida;

\section{Procedimento no Homem}

a) - lavar as mãos;

b) - reunir todo o material na bandeja e levá-lo junto ao paciente;

c) - explicar ao paciente o procedimento;

d) - cercar a cama com biombo, fechar portas e janelas;

e) - forrar a cama com o impermeável e sobre este o lençol, na altura dos quadrís do paciente;

f) - expor a região genital;

g) - calçar luvas;

h) - levantar o pênis com auxílio de gazes e fazer uma irrigação com água morna;

i) - expor a glande e ensaboar o pênis com auxílio de gazes, no sentido distal para proximal;

j) - desprezar as gazes utilizadas, no saco de lixo;

k) - enxaguar o pênis jogando água e retirar o excesso de sabão com auxílio de gazes, deixando o mais seco possível;

1) - colocar algumas gazes na cúpula e embebe-las com PVPI aquoso;

m)-expor a glande com a mão esquerda, para descobrir o orifício uretral;

n) - aplicar, com a outra mão, gaze embebida em PVPI aquoso, num sentido único distal para proximal, sem retornar a face já usada da gaze, repetindo três vezes o procedimento;

o) - secar com gaze o excesso de PVPI;

p) - desprezar as gazes utilizadas, em saco de lixo;

q) - retirar o algodão do tubo estéril, com cuidado para não contaminar a parte interna deste e a borda do tubo, segurando-os na mesma mão;

r) - expor a glande com a mão esquerda, até descobrir o orifício uretral e pedir ao paciente para que urine;

s) - colher o jato médio da micção diretamente no tubo estéril, não ultrapassando a metade deste;

t) - fechar o tubo com cuidado, para que a face contaminada do algodão fique para fora;

u) - apoiar o tubo em local seguro, para não cair;

v) - secar o pênis do paciente, com papel higiênico;

x) - recolher todo o material utilizado, deixando o ambiente em ordem e o paciente confortável;

y) - identificar o tubo com: nome completo do paciente, RG e no de leito, encaminhando-o em seguida.
Paciente adulto sem sonda vesical

- deambulante

\section{Material Necessário}

a) - bande ja;

b) - chuveiro de água morna oủ bidê;

c) - sabão líquido ou sabonete;

d) - PVPI aquoso;

e) - gazes;

f) - seringa de $20 \mathrm{ml}$;

g) - cúpula limpa;

\section{Procedimento na Mulher}

a) - lavar as mãos;

b) - reunir todo o material na bandeja e lavá-la ao banheiro;

c) - explicar à paciente o procedimento;

d) - pedir à paciente que faça uma lavagem externa no chuveiro, secando-se em seguida com toalha limpa;

e) - colocar algumas gazes na cúpula e embebêlas com PVPI aquoso;

f) - pedir à paciente que sente no vaso sanitário;

g) - oferecer à paciente as gazes embebidas em PVPI aquoso, orientando-a para a limpeza da região genital, idem procedimento anterior na mulher acamada;

h) - orientar a paciente para avisar quando for uninar, of erecendo cúpula para colher o jato médio da micção;

i) - colher uma amostra de 10 e $30 \mathrm{ml}$ de urina, diretamente da cúpula com a seringa e despejá-la no tubo estéril, tendo os mesmos cuidados citados anteriormente, para não contaminá-la;

j) - recolher todo o material utilizado, deixando o ambiente em ordem e a paciente à vontade, para terminar sua higiene;

k) -identificar o tubo com: nome completo da paciente, RG e no do leito, encaminhando-a em seguida.

\section{Procedimento no Homem}

a) - lavar as mãos;

b) - reunir todo o material na bandeja e levá-lo ao banheiro;

c) - explicar ao paciente o procedimento;

d) - pedir ao paciente que faça uma lavagem externa no chuveiro, secando-se em seguida com toalha limpa;

e) - colocar algumas gazes na cúpula e embebêlas com PVPI aquoso;

f) - of erecer ao paciente as gazes embebidas em PVPI aquoso, orientando-o para a limpeza do pênis, idem procedimento anterior no homem acamado;

g) - Oferecer o tubo estéril ao paciente, orientando-o para não tocar em sua borda e colher o jato médio da micção, não ultrapassando a metade do tubo;

h) - fechar o tubo com cuidado, para que a face contaminada do algodão fique para fora;

i) - recolher todo o material utilizado, deixando o ambiente em ordem e o paciente à vontade; 
j) - identificar o tubo com: nome completo do paciente, RG e no do leito, encaminhando-o em seguida;

\section{Criança sem sonda vesical e sem controle es- fincteriano}

\section{Material Necessário}

a) - bandeja;

b) - jarro com água morna;

c) - sabão líquido;

d) - PVPI aquoso;

e) - ampola de $10 \mathrm{ml}$ de água destilada;

f) - gazes;

g) - cúpula estéril;

h) - coletor de urina - sexo feminino ou masculino;

i) - saco plástico para lixo.

\section{Procedimento na criança do sexo feminino}

a) - lavar as mãos;

b) - reunir todo o material na bande ja e levá-lo junto à criança;

c) - explicar à criança o procedimento;

d) - retirar as fraldas da crianças;

e) - fazer uma boa higiene com água e sabão, utilizando as gazes;

f) - enxaguar com gaze bem úmida e após, deixar o mais seco possível;

g)-colocar algumas gazes na cúpula e embebê-las com PVPI aquoso;

h) - afastar os pequenos lábios, com a mão esquerda, para expor o orifício uretral;

i) - aplicar, com a outra mão, gaze embebida em PVPI aquoso, nos pequenos lábios e vagina e depois grandes lábios e monte pubiano, sempre num único sentido, de cima para baixo, sem retornar a face já usada da gaze, repetindo três vezes o procedimento;

j) - secar bem todo o períneo, com gaze;

k) - aplicar gaze embebida em água destilada estéril para retirar todo o PVPI, secando em seguida;

l) - desprezar as gazes utilizadas, no saco de lixo;

m) - colocar o coletor para sexo feminino na criança, sem contaminá-lo por dentro;

n) - aguardar a criança urinar;

o) - retirar o coletor, sem contaminá-lo e fechá-lo, dobrando a borda de modo que fixe, cola sobre cola;

p) - dobrar a parte superior novamente e fixar com fita adesiva, deixando-o em local seguro;

q) - Fazer a higiene da criança e colocar fraldas limpas;

r) - recolher todo o material utilizado, deixando o ambiente em ordem e a criança confortável;

s) - identificar o saco coletor com: nome completo da criança, RG e no do leito, encaminhando-a em seguida.

\section{Procedimento na criança do sexo masculino}

a) - lavar as mãos;

b) - reunir todo o material na bandeja e levá-lo junto à criança;

c) - explicar à criança o procedimento;

d) - retirar as fraldas da criança;

e) - fazer uma boa higiene com água e sabão, utilizando as gazes;

f) - enxaguar com gaze bem úmida e após, deixar o mais seco possível;

g) - colocar algumas gazes na cúpula e embebê-las com PVPI aquoso;

h) - expor a glande com a mão esquerda, para descobrir o orifício uretral;

i) - aplicar com a outra mão, gaze embebida em PVPI aquoso, na região da glande, pênis e escroto, num sentido único, sem retornar a face já usada da gaze, repetindo três vezes o procedimento;

j) - secar bem todo o períneo com gaze;

k) - aplicar gaze embebida em água destilada estéril, para retirar todo o PVPI, secando em seguida;

1) - desprezar as gazes utilizadas, no saco de lixo;

m) - colocar o coletor para sexo masculino na criança, sem contaminá-lo por dentro; aguardando a criança urinar;

o) - retirar o coletor, sem contaminá-lo e fechá-lo, dobrando a borda de modo que fixe cola sobre cola;

p) - dobrar a parte superior novamente e fixar com fita adesiva, deixando-o em local seguro;

q) - fazer a higiene da criança e colocar fraldas limpas;

r) - recolher todo o material utilizado, deixando o ambiente em ordem e a criança confortável;

s) - identificar o saco coletor com: nome completo da criança, RG e no do leito, encaminhando-o em seguida.

\section{Paciente com sonda vesical sistema fechado}

\section{Material Necessário}
a) - bandeja;
b) - PVPI aquoso;
c) - gazes;
d) - seringa de $20 \mathrm{ml}$ com agulha calibre 6 ou 7;
e) - tubo estéril para urocultura;

\section{Procedimento}

a) - lavar as mãos;

b) - reunir todo o material na bandeja e levá-lo junto ao paciente;

c) - explicar ao paciente o procedimento;

d) - realizar antissepsia da sonda, com gaze embebida em PVPI aquoso no local próprio para se puncionar, num sentido único, sem retornar a face já usada da gaze, repetindo três vezes o procedimento;

e) - desprezar as gazes utilizadas, no lixo;

f) - puncionar a borracha (própria do sistema fechado) e aspirar $10 \mathrm{ml}$; 
g) - retirar o algodão do tubo estéril, com cuidado para não contaminar a parte interna deste e a borda do tubo;

h) - despejar a urina no tubo estéril, fechando-o com cuidado, para que a face contaminada do algodão fique para fora;

i) - recolher todo o material utilizado, deixando o ambiente em ordem e o paciente confortável;

j) - identificar o tubo com: nome completo do paciente, RG, $\mathrm{n}^{\circ}$ do leito e colocar paciente sondado; encaminhar em seguida;

\section{Observações:}

- Em recém-nascidos (feminino), remover todo o vérnix da vulva.

- Em recém-nascidos (masculinos), expor ao máximo a glande, limpando bem para evitar que a urina se contamine com resíduos que ficam entre o prepúcio e a glande.

- Caso a mulher este ja menstruada ou apresentando secreção vaginal, usar tampão para evitar que haja contaminação com o sangue ou com a secreção e reforçar a higiene.

- Pacientes com AIDS: identificar a amostra por fora, com etiqueta escrito "AIDS". Encaminhar a amostra dentro de embalagem plástica.

- Pacientes com Nefrostomia: usar coletor infantil apos higiene externa com PVPI.

- Se não for possível encaminhar a amostra imediatamente, resfrigerar a $4^{\circ} \mathrm{C}$.

- Caso não haja tubo estéril, pode-se encaminhar a amostra em uma seringa descartável estéril, fechando com agulha encapada bem fixada.

- O volume mínimo necessário para crianças é de 5 ml. Em adultos, de preferência $10 \mathrm{ml}$.

- Incentivar o paciente para que faça sua propria higiene e ajude ativamente na coleta da urina.

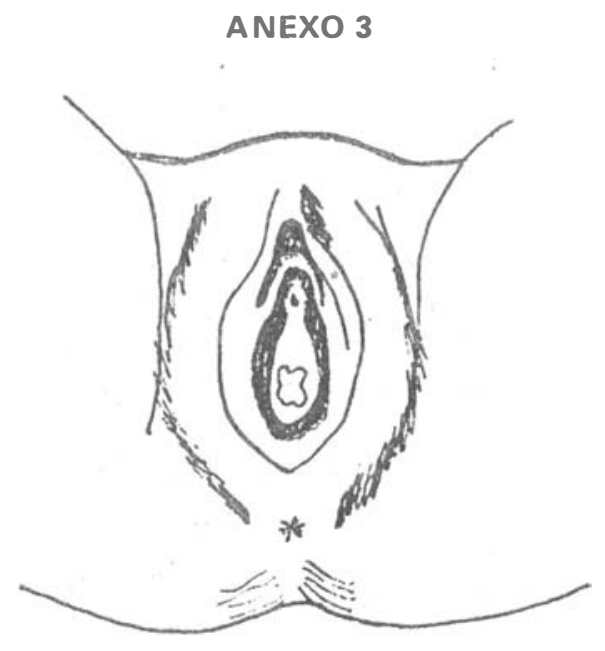

Região perineal feminina

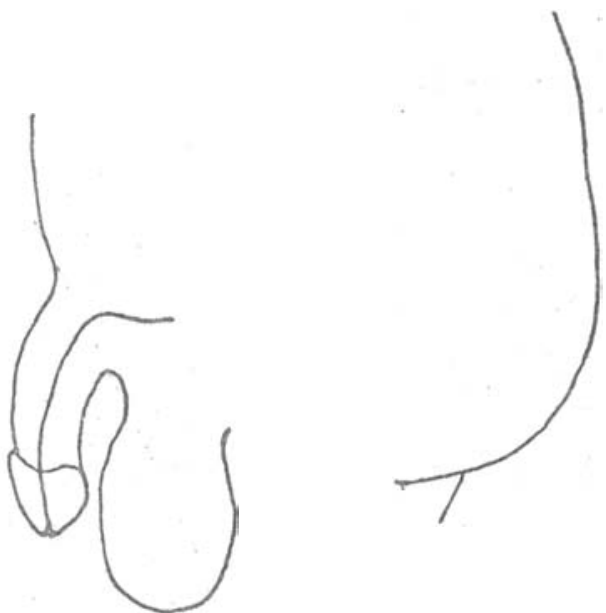

Região perineal masculina 


\section{REFERÊNCIAS BIBLIOGRÁFICAS}

1 ANDRIOLE, V.T. Infecções do Trato Urinário. Rio de Janeiro, Interlivros, 1988, p.ix.

2 EDEN, C.S., De MAN, P. - Virulência bacteriana na infecção do trato urinário. In: ANDRIOLE, V.T. Infeç̧ão do trato urinário. Rio de Janeiro, Interlivros, 1988, p. 19-40.

3 JOHNSON, J.R., S TAMM, W.E. Diagnóstica e tratamento das infecçōes agudas do trato urinário. In: ANDRIOLE, V.T. Infecçöes do trato urinário. Rio de Janeiro, Interlivros, 1988, p.63-82.

4 WALLACH, J. Interpretação dos diagnósticos de laboratorio. 3e, São Paulo, Ed. Manole, 1981, p. 170-171.

\section{BIBLIOGRAFIA CONSULTADA}

-BRUNNER, L.S., SUDDARTH, D.S. Afecções dos rins, do trato urinário e do sistema reprodutor. In: Enfermagem prática. 2e, Rio de Janeiro, Interamericana 1980, vol. 2, p. 584-593.

-Du GAS, B.W. Necessidade de eliminação urinária. In: Enfermagem prática. 4e., Rio de Janeiro, Interamericana, 1984, p. 212-231.

-S TAMM, W.E., Measurement of pyuria and its relation to bacteriúria $A M$. J.MED. 75: 53,1983. 7:431,1986. 